\title{
Decreased risk adjusted 30-day mortality for hospital admitted injuries: a multi- centre longitudinal study
}

\author{
Robert Larsen ${ }^{1,2,3,6^{*}}$ (D), Denise Bäckström ${ }^{1,4,5}$, Mats Fredrikson ${ }^{1}$, Ingrid Steinvall ${ }^{6}$, Rolf Gedeborg ${ }^{7}$ \\ and Folke Sjoberg ${ }^{1,2,3,6}$
}

\begin{abstract}
Background: The interpretation of changes in injury-related mortality over time requires an understanding of changes in the incidence of the various types of injury, and adjustment for their severity. Our aim was to investigate changes over time in incidence of hospital admission for injuries caused by falls, traffic incidents, or assaults, and to assess the risk-adjusted short-term mortality for these patients.
\end{abstract}

Methods: All patients admitted to hospital with injuries caused by falls, traffic incidents, or assaults during the years 2001-11 in Sweden were identified from the nationwide population-based Patient Registry. The trend in mortality over time for each cause of injury was adjusted for age, sex, comorbidity and severity of injury as classified from the International Classification of diseases, version 10 Injury Severity Score (ICISS).

Results: Both the incidence of fall (689 to 636/100000 inhabitants: $p=0.047$, coefficient -4.71 ) and traffic related injuries (169 to 123/100000 inhabitants: $p<0.0001$, coefficient -5.37 ) decreased over time while incidence of assault related injuries remained essentially unchanged during the study period. There was an overall decrease in risk-adjusted 30-day mortality in all three groups (OR 1.00; Cl95\% 0.99-1.00). Decreases in traffic (OR 0.95; 95\% Cl 0.93 to 0.97) and assault (OR 0.93; $95 \% \mathrm{Cl} 0.87$ to 0.99 ) related injuries was significant whereas falls were not during this 11-year period.

Discussion: Risk-adjustment is a good way to use big materials to find epidemiological changes. However after adjusting for age, year, sex and risk we find that a possible factor is left in the pre- and/or in-hospital care.

Conclusions: The decrease in risk-adjusted mortality may suggest changes over time in pre- and/or in-hospital care. A non-significantdecrease in risk-adjusted mortality was registered for falls, which may indicate that low-energy trauma has not benefited for the increased survivability as much as high-energy trauma, ie traffic- and assault related injuries.

Keywords: Risk-adjusted mortality, ICISS, Trauma, Injury, Nationwide, Epidemiological

\section{Background}

Substantial efforts have been made for decades to improve injury prevention and implement systematic improvements of trauma care [1], but it remains a challenge to measure the impacts of these efforts in terms of changes in injury incidence and mortality. It has been reported that trafficrelated mortality has decreased over time, but no such

\footnotetext{
* Correspondence: robert.larsen@liu.se

${ }^{1} 1$ Department of Clinical and Experimental Medicine, Linkoping University, Linkoping, Sweden

${ }^{2}$ Department of Anaesthesiology and Intensive Care, University Hospital Linkoping, Linkoping University, S-58185 Linkoping, Sweden

Full list of author information is available at the end of the article
}

improvement has been described for fall-related injuries [2]. In order to try to understand the potential impact of health care interventions on injury mortality it is essential to adjust for changes in injury incidence, injury severity, and patient baseline characteristics such as comorbidity.

For this study we elected to use the national patient registry, instead of a specialised trauma registry. This allows a nation-wide population-based approach and avoids some concerns regarding coverage and selection bias inherent for trauma registries. For all types of data sources concerns regarding the validity of data must be addressed. The International Classification of disease Injury Severity Score (ICISS) has been developed for use with large administrative 
registries [3, 4]. Using ICISS for risk adjustment accurately predicts the chance of survival, and is comparable to the Injury Severity Score (ISS) in trauma [5].

This study focuses on three causes of injury. Traffic injury is the dominant type of high-energy trauma causing hospital admission and has a substantial mortality rate. This injury type is therefore expected to be well suited to reflect the potential effects of an improved trauma care system, since these efforts have mainly focused on high-energy trauma. While falls are the most common cause of injury resulting in hospital admission, they are dominated by lowenergy trauma and are usually not targeted by the trauma care system. Falls, however, still have a large impact on public health and health-care consumption [6]. Injuries resulting from assault are the third category in focus for this study. Violence is one of the most common causes of death among young males worldwide [7]. Hospitalised victims of violent crimes, however, have lower mortality compared to traffic injury [8] and incidence can be expected to depend on other factors than those underlying traffic injury incidence.

The aim of the present study was to estimate changes in incidence and risk-adjusted mortality over time among patients in Sweden who were admitted to hospital with injuries caused by falls, traffic incidents, and assaults.

\section{Methods}

\section{Patients studied}

All hospital admissions for trauma caused by fall, traffic incident, or assault during the years 2001 to 2011 in Sweden were retrieved from the National Patient Registry. Patients who died before reaching hospital or who had injuries that did not require hospital admission were not included in the study population. For patients who were transferred between departments during treatment for the same injury we used the first record in the registry as the date of admission and diagnoses, and the last date of that admission for the date of discharge. All records with an International Classification of Diseases version 10 (ICD10) [9] main diagnosis in the range of S00-T80 (trauma diagnoses), excluding T78 (adverse effects), or with an external cause of injury in the range V01-Y98.9, were selected during the first step. These records were linked to all records in the Cause of Death Registry that had "injury" as the main cause of death (V01-Y98.9). Records with missing information on age, sex, date of admission, or mechanism of injury were excluded from the analyses.

Records in which the cause of injury was "fall" (W00W19), "traffic incident" (V01-V99), or "assault" (X85Y09) were then selected for further study (Fig. 1). A few observations $(n=292,0.036 \%)$ were classified in more than one of the groups, and they were excluded.

The National Patient Registry covers all admissions to Swedish hospitals since 1987, [10] and the Cause of Death Registry covers all deaths of Swedish citizens. Records were linked using each person's unique personal identification number, which is given to everyone who has their permanent residence in Sweden [11].

\section{Identification of death and 30-day mortality}

Data from the Causes of Death Registry were available until 31 December 2012, which allowed at least 12 months' follow-up after the date of admission to hospital, which

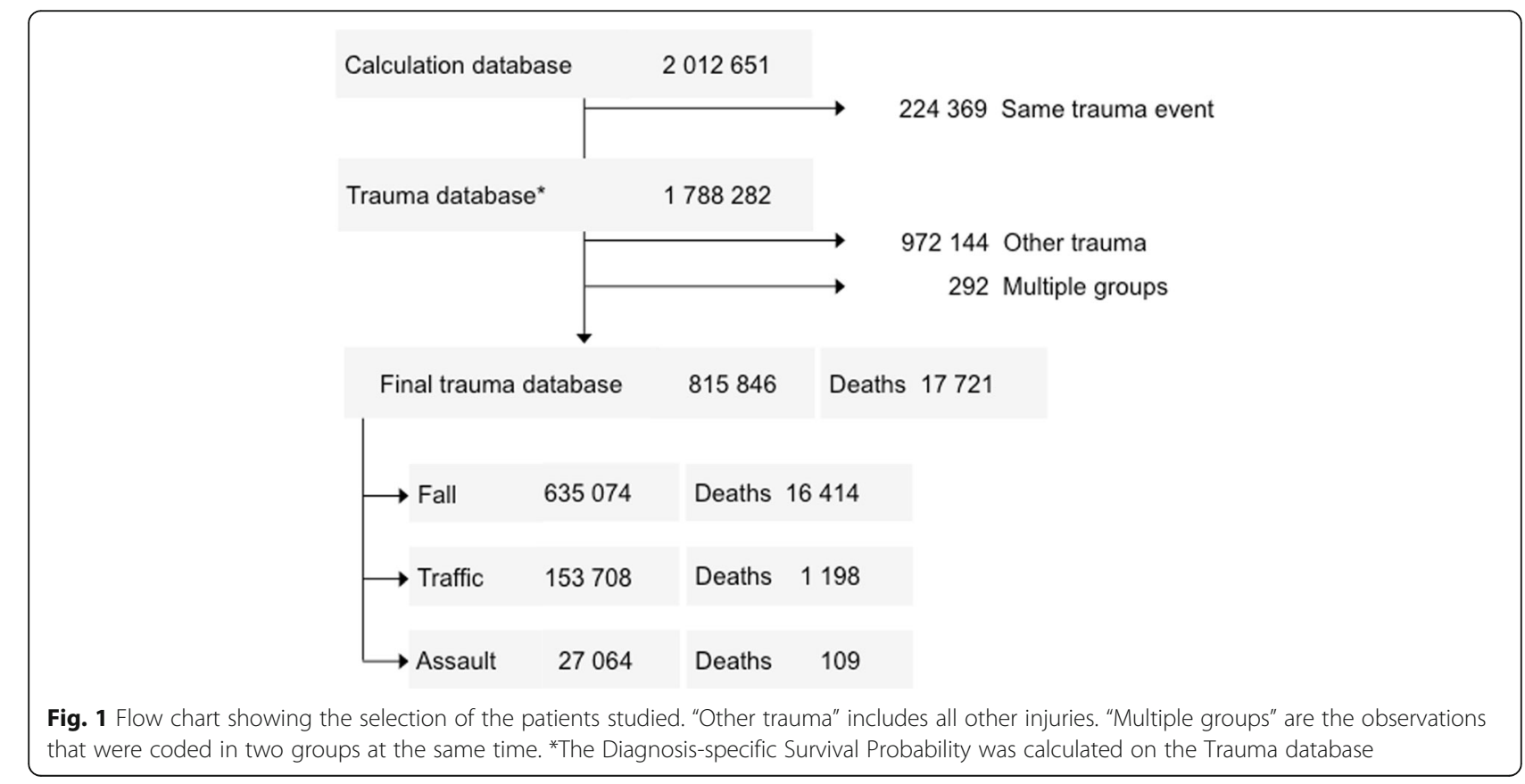


was considered the index date of the injury. Mortality was calculated based on the date of death being within 30 days of the index date (30-day mortality) to include most of the patients who died as a direct result of the injury, and to exclude those who died mainly of other causes [12-14].

\section{Severity of injury}

The Injury Severity Score (ISS) has long been regarded as the standard measure of injury severity. In 1996 Osler et al. developed a score based on ICD-9 hospital discharge diagnoses (ICISS), so that they could use big databases with diagnostic codes that had been recorded for administrative purposes [5]. Later studies showed that ICISS calculated from ICD10 was superior $[15,16]$ and allowed a more accurate estimate of severity of injury [3]. Since then ICISS has been used and evaluated several times both at the European level and in Sweden. [8, 17-22]. A recent meta-analysis also supports the value of this methodology to assess trauma mortality outcome [23].

The Diagnosis-specific Survival Probability (DSP in the formula below) is the proportion of patients with a specific injury code who survived 30 days after the first admission. We omitted duplicate ICD10 codes from the National Patient Registry before we calculated the survival probability. The DSPs were estimated from all injured patients whose details had been primarily extracted from our trauma/injury database, using the main injury diagnosis codes and up to nine secondary codes. The ICISS for individual cases were calculated as the product of DSPs corresponding to the patient's injury codes (that is, the product of each probability for survival after the injury).

$$
\begin{aligned}
\mathrm{ICISS}= & \mathrm{DSP}_{\text {main diagnosis }} \\
& \times \mathrm{DSP}_{\text {secondary diagnosis } 1} \\
& \times \mathrm{DSP}_{\text {secondary diagnosis } 2} \\
& \times \mathrm{DSP}_{\text {secondary diagnosis... }}
\end{aligned}
$$

\section{Comorbidity}

The Charlson Comorbidity Index (CCI) was calculated using the scale in the original article as described [24] and the ICD-codes from Christensen et al. [25].

\section{Statistical modelling}

To adjust mortality for the severity of injury, the ICISS was used in logistic regression models of 30-day mortality. In the second step we added the sex and age groups to improve the predictive value of the model [17] and to adjust for confounding [26]. A third step included the CCI [24] in the regression model, and as a final step we added calendar year as a covariate in the model.

\section{Statistical analysis}

Incidence $/ 100000$ person-years was calculated using national data retrieved from the Statistics Sweden open database for population [27]. The coefficient of variation for estimates of incidence over time was calculated as the ratio of the SD to the mean. Linear regression was used to estimate the trend in incidence of injuries over time. All the models used logistic regression for 30-day mortality.

The discrimination is the model's ability to separate those who died from those who survived, which was measured by calculation of the area under the receiver operating characteristic curve (AUC) using the C statistic.

Because ICISS may not have a linear relation with the logit of mortality, [28] ICISS and year were modelled both as a linear effect and as a restricted cubic spline in the logistic regression models.

We used the statistics software Stata (StataCorp LP. 2011-15. Stata version 12-14. College Station, TX, USA) for data management and statistical analyses. Probabilities of less than 0.05 were accepted as significant.

\section{Results}

\section{Patient characteristics}

The final study population consisted of 815,846 hospital admissions for the three causes of injury. The age span ranged from 0 to 111 years, mean (SD) age 58 (29) years. "Fall" was the largest group and "assaults" the smallest. More women than men presented with a fall, whereas in the traffic incident and assault groups there were more men. There is a predominance of older people in fall-related injuries whereas the younger ones were more likely to sustain traffic-incident-related and assault-related injuries (Table 1).

Table 1 Characteristics of patients by cause of injury

\begin{tabular}{llll}
\hline Variable & Fall & Traffic & Assault \\
\hline Patients & $635,074(78)$ & $153,708(19)$ & $27,064(3)$ \\
Male & $259,759(41)$ & $93,186(61)$ & $20,866(77)$ \\
Age in years, mean (SD) & $64(27)$ & $37(22)$ & $33(15)$ \\
Age & & & \\
$0-14$ & $70,162(11)$ & $23,966(16)$ & $1007(4)$ \\
$15-25$ & $27,513(4)$ & $38,259(25)$ & $10,480(39)$ \\
$26-35$ & $17,937(3)$ & $19,627(13)$ & $5360(20)$ \\
$36-45$ & $25,356(4)$ & $19,197(12)$ & $4425(16)$ \\
$46-55$ & $38,657(6)$ & $17,295(11)$ & $3403(13)$ \\
$56-65$ & $61,672(10)$ & $14,557(9)$ & $1540(6)$ \\
$66-75$ & $82,697(13)$ & $9805(6)$ & $527(2)$ \\
76 and over & $311,080(49)$ & $11,002(7)$ & $322(1)$ \\
\hline
\end{tabular}

Data are number (\%) unless otherwise stated 


\section{Incidence}

The crude numbers of patients/year remained almost constant during the study period, the biggest variation being in the "traffic incidents" group (coefficient of variation 11\%). Figure 2 shows the incidence of injury throughout the period. Linear regression analyses showed that fall-related injuries decreased from 689 to 636 hospital admissions / 100,000 inhabitants $(p=0.047$, annual mean decrease of $4.71,95 \%$ confidence interval (CI) -9.93 to 0.06 ), and traffic-incident-related ones from 169 to 123 observations/ 100000 inhabitants, $(p<0.0001$, annual mean decrease of $5.37,95 \%$ CI -6.91 to -3.82$)$. The incidence of assaultrelated injuries remained almost unchanged over the period (from 25 to 26 hospital admissions/100000 inhabitants, $p=$ 0.45 , annual mean increase of $0.11,95 \% \mathrm{CI}-0.21$ to 0.43 ). The variability between years probably resulted from the limited number of observations in the assault group.

\section{Mortality}

The crude overall mortality in the study population remained relatively stable over time (Fig. 3a) (from 17 to 17 dead within 30 days $/ 100000$ inhabitants, $p=0.72$ ). The crude traffic-related mortality decreased (from 1.3 to 0.9 dead within 30 days $/ 100000$ inhabitants, $p=0.008$, linear regression coefficient -0.056 see Fig. 3b), as opposed to falls and assaults that remained roughly stable over the study period, although with a large variability in the subgroup with assault injuries.

\section{Risk-adjusted mortality}

Calendar time (year) was not an independent risk factor for mortality within 30 days when adjusted for age, injury severity (ICISS), and CCI (Table 2).

The model also suggests that the risk for death within 30 days may be higher following fall injury (OR 1.41; 95\% CI 1.14 to 1.74), and lower following traffic injury (OR 0.90; 95\% CI 0.73 to 1.12 ), using assault as the reference category.

Modelling death within 30 days for each subgroup suggests an annual decrease of mortality risk for trafficrelated injuries (OR $0.95 ; 95 \%$ CI 0.93 to 0.97 ), and an annual decrease of mortality risk for assault-related injuries (OR 0.93; 95\% CI 0.87 to 0.99). The risk for death within 30 days after fall-related injuries did not appear to change over the study period (OR 1.00, 95\% CI 0.99 to 1.00). Age and sex were independent risk factors for mortality in fall-related and traffic-incident-related injuries, but not in assaults (Tables 3, 4 and 5).

In sensitivity analyses ICISS and year were also modelled as restricted cubic splines in the logistic regression models with similar results (data not shown).

The discriminative value (C-statistics, AUC) of the logistic regression model for death within 30-days including age, sex, year, ICISS and CCI was 0.876 when applied to the entire study population. Subgroup analyses showed an
AUC of 0.858 among the fall-related injuries, an AUC of 0.923 among traffic-incident-related injuries, and an AUC of 0.875 among the assault-related injuries.

\section{Discussion}

Using nation-wide health-care registries we identified patients admitted to hospital with injuries caused by falls, traffic incidents, or assaults during an 11-year period. The incidence of fall- and traffic-related injuries decreased over the study period, but there were no notable change in the incidence of assault-related injuries. There was a decrease in mortality risk following traffic-related and assaultrelated injuries over time, independent of injury severity and baseline patient characteristics such as comorbidity. This may suggest that there have been improvements in prehospital and/or in-hospital management of these injuries. No decrease was, however, seen in the mortality risk following fall-related injuries. These injuries are mainly due to low-energy trauma and may not benefit from management strategies developed for high-energy trauma.

\section{Strengths of the study}

The population-based design with reliable follow-up based on the exact person-based linkage of hospital discharge records with cause of death data, and accurate estimates of the injury severity are notable strengths of this study. The ICISS provides an accurate estimation of the severity of injury [3]. The quality of underlying coding of injuries in the Swedish National Patient Registry has been validated previously, and is accurate to the fourth position of the code [29].

\section{Limitations of the study}

One limitation of the study is that some types of injury are rare, even in a nationwide study, which adds uncertainty to estimates of the severity of injury. A previous study showed that probabilities of diagnosis-specific survival are to a large extent comparable between data from Sweden and the USA [17]. A comparison among eight countries also suggested substantial similarities between countries in terms of ICISS [17]. Another limitation is that the data is collected from a high income country and may not be applicable to middle- or low-income countries The trends in risk-adjusted mortality may reflect changes in the quality of care, but such an interpretation must be cautious, and it is not possible to identify from this study which specific components of care may be of importance. Since the study does not include pre-hospital deaths the design may be less well suited to detect impact of pre-hospital interventions [30, 31]. Further limitations include that this dataset has not been calibrated, but when using the ICISS-method it is rarely done. Finally one could imagine that patients readmitted and deceased after our 30-day limit would 


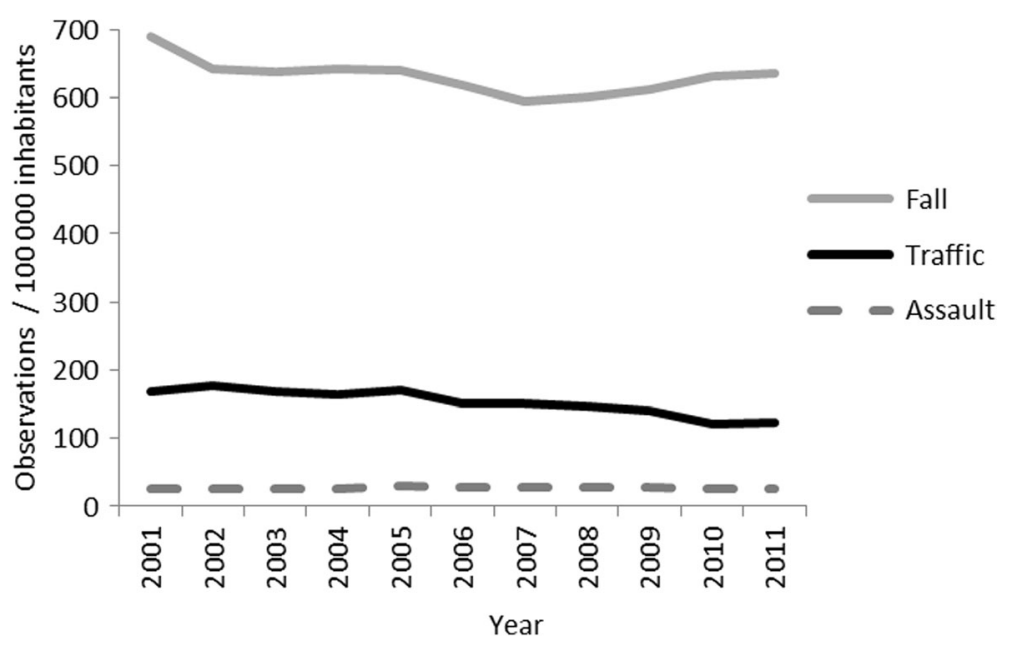

Fig. 2 The incidence of injuries /100000 person years over the period by mechanism of injury

change the dataset, however when doing calculations for 90-day mortality (data not shown) the differences were very small. As with all registry data some caution needs to be made regarding data input quality. This issue has been discussed previously for data from the National Swedish Registry [10].

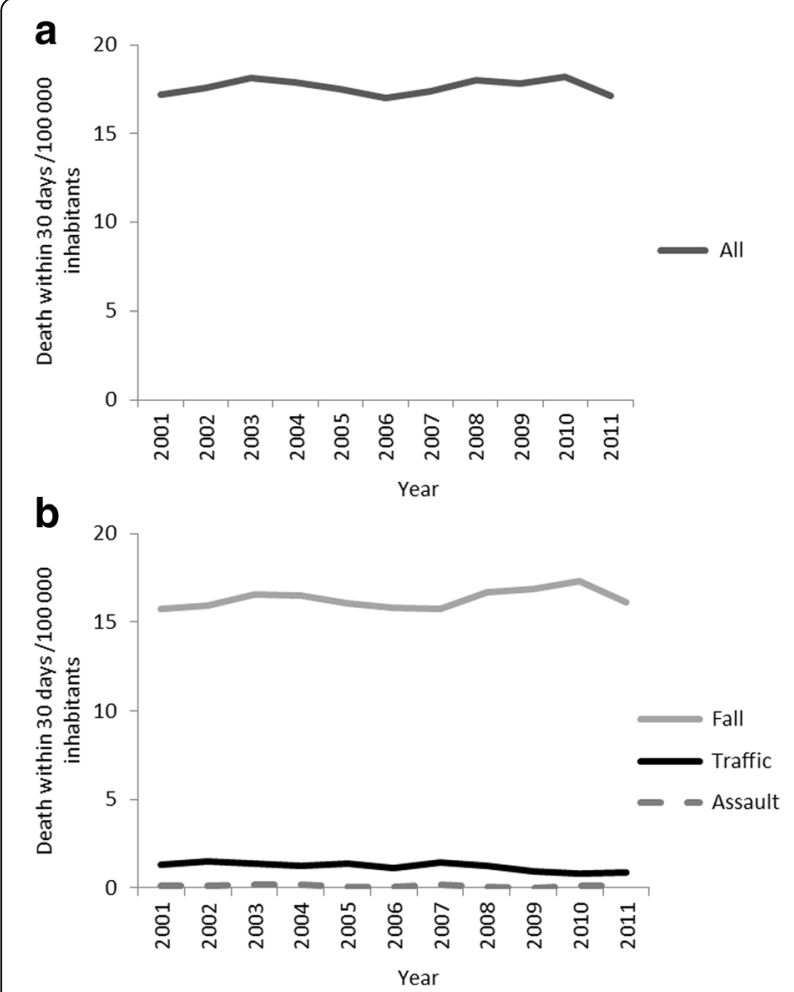

Fig. 3 a. Crude incidence of death within 30 days (total number of deaths/100000 inhabitants). b. Crude incidence of 30-day mortality/ 100000 inhabitants of injuries over the years by mechanism of injury
Strengths, weaknesses, and important differences in results compared with other studies

It has previously been shown that Sweden compares well with other countries in the recording and outcome of injury [17]. Even though coding-errors in ICD-10 are common, the consequences for estimates of the severity of injury were minor in most cases [29].

An increase in the incidence of fall-related, and a decrease in that of traffic-incident-related injuries has previously been reported from the USA [2, 32]. The countries differ in incidence as Sweden has roughly twice the incidence of falls, and a tenth the incidence of traffic-incident-related injuries than the USA [2].

In addition, the incidence of fall-related injuries is difficult to compare with those of other studies because of different inclusion criteria. Most previous studies have focused on a small group, such as those who present to emergency departments, older people, or those with specific fractures, [33-35] whereas this population-based study has included all fall-related admissions to hospital. Crude mortality after fall-related injuries in Sweden is up to twice that in the USA [2]. Some studies have reported no change over time, [32] while we found a small decrease in incidence. This finding is however uncertain due to the limited precision in this estimation.

The incidence of traffic-incident-related injuries estimated in this study is not limited to motor vehicle traffic as it is in the National Trauma Data Bank (NTDB) in the USA, [2] but it includes all traffic-related injuries. Nevertheless our data indicate a mortality that is roughly one tenth of that reported by the NTDB [2]. This difference must be interpreted with caution, because the effect of selection bias among NTDB data is not known but previously published articles has included both preand in-hospital death (no exclusion date in mortality stated). Despite the difference in absolute incidence, the 
Table $\mathbf{2}$ Logistic regression for death within 30 days after admission (fall, traffic and assault), risk adjusted by ICISS

\begin{tabular}{lllll}
\hline & OR & $p$ & $95 \% \mathrm{Cl}$ & $95 \% \mathrm{Cl}$ \\
\hline ICISS & $7.20 \mathrm{e}-06$ & $<0.001$ & $5.93 \mathrm{e}-06$ & $8.75 \mathrm{e}-06$ \\
Sex (male as reference) & 0.54 & $<0.001$ & 0.53 & 0.56 \\
$\mathrm{CCl}$ & 1.25 & $<0.001$ & 1.24 & 1.27 \\
Year & 1.00 & 0.008 & 0.99 & 1.00
\end{tabular}

Age, reference is $0-14$ years

$\begin{array}{ccccc}15-25 & 4.04 & <0.001 & 2.78 & 5.86 \\ 26-35 & 3.78 & <0.001 & 2.56 & 5.60 \\ 36-45 & 3.87 & <0.001 & 2.63 & 5.69 \\ 46-55 & 5.89 & <0.001 & 4.08 & 8.49 \\ 56-65 & 8.83 & <0.001 & 6.20 & 12.58 \\ 66-75 & 20.11 & <0.001 & 14.21 & 28.45 \\ 76 \text { and older } & 70.76 & <0.001 & 50.20 & 99.76 \\ \text { Fall } & 1.41 & 0.001 & 1.14 & 1.74 \\ \text { Traffic } & 0.90 & 0.340 & 0.73 & 1.12 \\ \text { Assault } & 1.00 & & & \end{array}$

$n=815,846$

Abbreviations: CCI Charlson Comorbidity Index, CI Confidence Interval, ICISS International Classification of disease Injury Severity Score, OR Odds Ratio

focus in our analyses is on the change in mortality over time. After adjusting for other risk factors such as injury severity and comorbidity, there was still a decrease in mortality among the traffic-related injuries. A possible explanation may be an improvement in prehospital or in-hospital care, but this remains largely speculative.

In assault-related injuries, most previous studies have focused on specific mechanisms such as firearms, [36, 37]

Table 4 Logistic regression for death within 30 days after admission (traffic), risk adjusted by ICISS

\begin{tabular}{lllll}
\hline & OR & $p$ & $95 \% \mathrm{Cl}$ & $95 \% \mathrm{Cl}$ \\
\hline ICISS & $1.27 \mathrm{e}-05$ & $<0.001$ & $8.76 \mathrm{e}-06$ & .0000183 \\
Sex (male as reference) & 0.69 & $<0.001$ & 0.60 & 0.79 \\
CCI & 1.22 & $<0.001$ & 1.11 & 1.33 \\
Year & 0.95 & $<0.001$ & 0.93 & 0.97
\end{tabular}

Age, reference is $0-14$ years

\begin{tabular}{lllll}
$15-25$ & 1.69 & 0.012 & 1.13 & 2.56 \\
$26-35$ & 1.56 & 0.049 & 1.00 & 2.41 \\
$36-45$ & 1.81 & 0.007 & 1.17 & 2.80 \\
$46-55$ & 2.37 & $<0.001$ & 1.55 & 3.63 \\
$56-65$ & 2.88 & $<0.001$ & 1.89 & 4.40 \\
$66-75$ & 5.26 & $<0.001$ & 3.47 & 7.97 \\
76 and older & 14.47 & $<0.001$ & 9.78 & 21.41 \\
ICISS & $1.64 \mathrm{e}-05$ & $<0.001$ & $4.97 \mathrm{e}-06$ & .0000544 \\
\hline
\end{tabular}

$n=153708$

Abbreviations: CCI Charlson Comorbidity Index, $\mathrm{Cl}$ Confidence Interval, ICISS International Classification of disease Injury Severity Score, OR Odds Ratio
Table 3 Logistic regression for death within 30 days after admission (fall), risk adjusted by ICISS

\begin{tabular}{lllll}
\hline & OR & $p$ & $95 \% \mathrm{Cl}$ & $95 \% \mathrm{Cl}$ \\
\hline ICISS & $6.06 \mathrm{e}-06$ & $<0.001$ & $4.81 \mathrm{e}-06$ & $7.65 \mathrm{e}-06$ \\
Sex (male as reference) & 0.53 & $<0.001$ & 0.52 & 0.55 \\
CCI & 1.24 & $<0.001$ & 1.23 & 1.26 \\
Year & 1.00 & 0.195 & 0.99 & 1.00
\end{tabular}

Age, reference is $0-14$ years

\begin{tabular}{lllll}
$15-25$ & 13.42 & $<0.001$ & 4.04 & 44.57 \\
$26-35$ & 14.11 & $<0.001$ & 4.17 & 47.71 \\
$36-45$ & 15.25 & $<0.001$ & 4.65 & 50.06 \\
$46-55$ & 38.08 & $<0.001$ & 12.10 & 119.82 \\
$56-65$ & 69.85 & $<0.001$ & 22.41 & 217.67 \\
$66-75$ & 167.16 & $<0.001$ & 53.82 & 519.24 \\
76 and older & 587.07 & $<0.001$ & 189.26 & 1821.05 \\
\hline
\end{tabular}

$n=635074$

Abbreviations: CCI Charlson Comorbidity Index, CI Confidence Interval, ICISS International Classification of disease Injury Severity Score, OR Odds Ratio

but because of the low incidence of such injuries in Sweden it is difficult to compare specific mechanisms of injury with other countries $[2,38]$. As in the other groups, the decrease in risk-adjusted mortality in this group may also be related to improvements in pre-hospital or inhospital care but may also reflect residual confounding from trends in specific injury mechanisms within the broad category of assault injuries still unadjusted for.

Although this study was not designed to evaluate changes in medical treatment, improvement in prehospital or in-hospital remain a possible explanation for the remaining reduction in mortality over time seen after adjusting for age, sex, injury severity, and comorbidities.

Table 5 Logistic regression for death within 30 days after admission (assault), risk adjusted by ICISS

\begin{tabular}{lllll}
\hline & OR & $p$ & $95 \% \mathrm{Cl}$ & $95 \% \mathrm{Cl}$ \\
\hline ICISS & $1.64 \mathrm{e}-05$ & $<0.001$ & $4.97 \mathrm{e}-06$ & .0000544 \\
Sex (male as reference) & 0.66 & 0.129 & 0.39 & 1.13 \\
$\mathrm{CCl}$ & 1.46 & 0.022 & 1.06 & 2.02 \\
Year & 0.93 & 0.022 & 0.87 & 0.99
\end{tabular}

Age, reference is $0-14$ years

\begin{tabular}{lllll}
$15-25$ & 0.75 & 0.695 & 0.17 & 3.24 \\
$26-35$ & 1.07 & 0.929 & 0.24 & 4.71 \\
$36-45$ & 1.08 & 0.921 & 0.24 & 4.77 \\
$46-55$ & 2.02 & 0.347 & 0.47 & 8.80 \\
$56-65$ & 2.92 & 0.161 & 0.65 & 13.10 \\
$66-75$ & 2.64 & 0.253 & 0.50 & 14.00 \\
76 and older & 12.33 & 0.001 & 2.67 & 57.01 \\
\hline
\end{tabular}

$n=27,064$
Abbreviations: $C C I$ Charlson Comorbidity Index, CI Confidence Interval, ICISS International Classification of disease Injury Severity Score, OR Odds Ratio 


\section{Meaning of the study: Possible explanations and implications for clinicians and policymakers}

This study has indicated a decrease in mortality risk for traffic-, and assault-related injuries over time, independent of age, sex, injury severity, and comorbidities. One potential interpretation is that this reflects improvements over time in prehospital or in-hospital care, or both. No such improvement is seen for fall-related injuries.

\section{Unanswered questions and future research}

The independent contribution of different preventive measures and improvements in interventions in healthcare require further study. In our analyses, sex was a significant risk factor for mortality in most groups. While the evaluation of specific health-care interventions [39] should be studied, it is also important to try to understand the mechanism behind the observed association between sex and mortality after injury, because that association was independent of both severity and mechanism of injury. Comorbidity was another independent risk factor and that needs to be further investigated.

\section{Conclusion}

In this population-based study over an 11-year period the incidence of fall- and traffic related-injuries decreased. Risk-adjusted 30-day mortality risk after traffic- and assault-related injuries decreased over time while mortality following fall-related injury remained unchanged over time. This may suggest improved performance of health care interventions mainly targeting high-energy trauma such as traffic- and assault-related injuries.

\section{Abbreviations \\ AUC: Area Under the Curve; CCl: Charlson Comorbidity Index; Cl: Confidence Interval; DSP: Diagnosis-specific Survival Probability; ICD-9/10: International Classification of Disease version 9/10; ICISS: International Classification of disease Injury Severity Score; ISS: Injury Severity Score; NTDB: National Trauma Data Base; OR: Odds Ratio; SD: Standard Deviation}

\section{Acknowledgements}

Not applicable.

\section{Funding}

This work was supported by, and done at, the Burn Centre, Department of Plastic Surgery, Hand Surgery, and Burns, and the Linkoping University, Linkoping, Sweden. The funders had no role in study design, data collection and analysis, decision to publish, or preparation of the manuscript.

\section{Availability of data and materials}

The data that support the findings of this study are available on request from the corresponding author [RL]. The data are not publicly available due to them containing information that could compromise "research participant privacy".

\section{Authors' contributions}

Study design: RL, RG, FS. Data collection: RL. Data analysis: RL, DB, MF. Data interpretation: RL, DB, MF, IS, RG, FS. Writing: RL, DB, IS, RG, FS. Critical revision: RL, $\mathrm{DB}, \mathrm{MF}, \mathrm{IS}, \mathrm{RG}, \mathrm{FS}$. The manuscript has been seen and approved by all authors.
Ethics approval and consent to participate

The study was approved by the Regional Ethics Review Board in Linkoping, Sweden.

\section{Consent for publication}

Not applicable.

\section{Competing interests}

No conflicts of interest where declared by the authors. However Rolf Gedeborg is also employed by the Medical Products Agency, an agency of the Swedish government. The views expressed in this paper may not reflect the views of the Medical Products Agency.

\section{Publisher's Note}

Springer Nature remains neutral with regard to jurisdictional claims in published maps and institutional affiliations.

\section{Author details}

${ }^{1} 1$ Department of Clinical and Experimental Medicine, Linkoping University, Linkoping, Sweden. ${ }^{2}$ Department of Anaesthesiology and Intensive Care, University Hospital Linkoping, Linkoping University, S-58185 Linkoping, Sweden. ${ }^{3}$ Department of Medical and Health Sciences, Linkoping University, Norrkoping, Sweden. ${ }^{4}$ Department of Anaesthesiology and Intensive Care, Linkoping University, Norrkoping, Sweden. ${ }^{5}$ Department of Medical and Health Sciences, Linkoping University, Norrkoping, Sweden. ${ }^{6}$ Department of Hand Surgery, Plastic Surgery and Burns, Linkoping University, Linkoping, Sweden. ${ }^{7}$ Department of Surgical Sciences, Anaesthesiology and Intensive Care, Uppsala University, Uppsala, Sweden.

Received: 31 August 2017 Accepted: 1 March 2018

Published online: 03 April 2018

\section{References}

1. MacKenzie EJ. Epidemiology of injuries: current trends and future challenges. Epidemiol Rev. 2000;22:112-9.

2. Sise RG, Calvo RY, Spain DA, Weiser TG, Staudenmayer KL. The epidemiology of trauma-related mortality in the United States from 2002 to 2010. J Trauma Acute Care Surg. 2014;76:913-9. discussion920

3. Stephenson S, Henley G, Harrison JE, Langley JD. Diagnosis based injury severity scaling: investigation of a method using Australian and New Zealand hospitalisations. Inj Prev. 2004;10:379-83.

4. Osler TM, Cohen M, Rogers FB, Camp L, Rutledge R, Shackford SR. Trauma registry injury coding is superfluous: a comparison of outcome prediction based on trauma registry International Classification of Diseases-Ninth Revision (ICD-9) and hospital information system ICD-9 codes. J Trauma. 1997:43:253-6. discussion256-7

5. Osler T, Rutledge R, Deis J, Bedrick E. ICISS: an international classification of disease-9 based injury severity score. J Trauma. 1996:41:380-6. discussion386-8

6. Hartholt KA, van Beeck EF, Polinder S, van der Velde N, Van Lieshout EMM, Panneman MJM, et al. Societal Consequences of Falls in the Older Population: Injuries, Healthcare Costs, and Long-Term Reduced Quality of Life. J Trauma Acute Care Surg. 2011;71:748-53.

7. Patton GC, Coffey C, Sawyer SM, Viner RM, Haller DM, Bose K, et al. Global patterns of mortality in young people: a systematic analysis of population health data. Lancet. 2009:374:881-92.

8. Gedeborg R, Chen L-H, Thiblin I, Byberg L, Melhus H, Michaëlsson K, et al. Prehospital injury deaths - Strengthening the case for prevention. J Trauma Acute Care Surg. 2012:72:765-72.

9. WHO Library Cataloguing-in-Publication Data. International Statistical Classification of Diseases and Related Health Problems. - 10th revision, ed 2010. 3v. Malta 2011 pp1-201

10. Ludvigsson JF, Andersson E, Ekbom A, Feychting M, Kim J-L, Reuterwall C, et al. External review and validation of the Swedish national inpatient register. BMC Public Health. 2011;11:450.

11. Ludvigsson JF, Otterblad-Olausson P, Pettersson BU, Ekbom A. The Swedish personal identity number: possibilities and pitfalls in healthcare and medical research. Eur J Epidemiol. 2009;24:659-67.

12. Ghorbani P, Falkén M, Riddez L, Sundelöf M, Oldner A, Strömmer L. Clinical review is essential to evaluate 30-day mortality after trauma. Scand J Trauma Resusc Emerg Med. 2014;22:18. 
13. Skaga NO, Eken T, Jones JM, Steen PA. Different definitions of patient outcome: Consequences for performance analysis in trauma. Injury. 2008;39: 612-22.

14. Van Haren RM, Thorson CM, Curia E, Schulman Cl, Namias N, Livingstone AS, et al. Impact of definitions on trauma center mortality rates and performance. J Trauma Acute Care Surg. 2012;73:1512-6.

15. Rutledge R, Osler T, Emery S, Kromhout-Schiro S. The end of the Injury Severity Score (ISS) and the Trauma and Injury Severity Score (TRISS): ICISS, an International Classification of Diseases, ninth revision-based prediction tool, outperforms both ISS and TRISS as predictors of trauma patient survival, hospital charges, and hospital length of stay. J Trauma. 1998:44:41-9.

16. Gagné M, Moore L, Beaudoin C, Batomen Kuimi BL, Sirois M-J. Performance of ICD-based injury severity measures used to predict in-hospital mortality: a systematic review and meta-analysis. J Trauma Acute Care Surg. 2016;80: 419-26

17. Gedeborg R, Warner M, Chen L-H, Gulliver P, Cryer C, Robitaille Y, et al. Internationally comparable diagnosisspecific survival probabilities for calculation of the ICD-10-based Injury Severity Score. J Trauma Acute Care Surg. 2014;76:358-65.

18. Gedeborg R, Svennblad B, Byberg L, Michaëlsson K, Thiblin I. Prediction of mortality risk in victims of violent crimes. Forensic Sci. Int. 2017:281:92-7.

19. Davie G, Cryer C, Langley J. Improving the predictive ability of the ICDbased Injury Severity Score. Inj Prev. 2008;14:250-5.

20. Petrey LB, Weddle RJ, Richardson B, Gilder R, Reynolds M, Bennett M, et al. Trauma patient readmissions: Why do they come back for more? J Trauma Acute Care Surg. 2015;79:717-24. discussion724-5

21. Moore L, Stelfox HT, Turgeon AF, Nathens AB, Lavoie A, Bourgeois G, et al. Derivation and validation of a quality indicator for 30-day unplanned hospital readmission to evaluate trauma care. J Trauma Acute Care Surg. 2014:76:1310-6

22. Moore L, Lavoie A, Bourgeois G, Lapointe J. Donabedian's structure-processoutcome quality of care model: Validation in an integrated trauma system. J Trauma Acute Care Surg. 2015;78:1168-75.

23. Gagné M, Moore L, Beaudoin C, Batomen Kuimi BL, Sirois M-J. Performance of International Classification of Diseases-based injury severity measures used to predict in-hospital mortality: A systematic review and meta-analysis. J Trauma Acute Care Surg. 2016;80:419-26.

24. Charlson ME, Pompei P, Ales KL, MacKenzie CR. A new method of classifying prognostic comorbidity in longitudinal studies: development and validation. J Chronic Dis. 1987:40:373-83.

25. Christensen S, Johansen MB, Christiansen CF, Jensen R, Lemeshow S Comparison of Charlson comorbidity index with SAPS and APACHE scores for prediction of mortality following intensive care. Clin Epidemiol. 2011;3:203-11.

26. Victorino GP, Chong TJ, Pal JD. Trauma in the elderly patient. Arch Surg. 2003;138:1093-8.

27. Statistics Sweden. Population by age and sex.http://www.statistikdatabasen. scb.se/pxweb/en/ssd/START_BE_BE0101_BE0101A/BefolkningR1860/ ?rxid=3858e946-350b-40e0-bf56-f21a52a9562d. Accessed 3 Jun 2016

28. Moore L, Lavoie A, Bergeron E, Emond M. Modeling Probability-Based Injury Severity Scores in Logistic Regression Models: The Logit Transformation Should Be Used. J Trauma. 2007;62:601-5.

29. Bergström MF, Byberg L, Melhus H, Michaëlsson K, Gedeborg R. Extent and consequences of misclassified injury diagnoses in a national hospital discharge registry. Inj. Prev. 2011;17:108-13.

30. Blomberg H, Svennblad B, Michaelsson K, Byberg L, Johansson J, Gedeborg R. Prehospital Trauma Life Support Training of Ambulance Caregivers and the Outcomes of Traffic-Injury Victims in Sweden. ACS. 2013;217:1010-2.

31. Johansson J, Blomberg H, Svennblad B, Wernroth L, Melhus H, Byberg L, et al. Prehospital Trauma Life Support (PHTLS) training of ambulance caregivers and impact on survival of trauma victims. Resuscitation. 2012;83: 1259-64.

32. Potenza BM, Hoyt DB, Coimbra R, Fortlage D, Holbrook T, HollingsworthFridlund $\mathrm{P}$, et al. The epidemiology of serious and fatal injury in San Diego County over an 11-year period. Journal Trauma. 2004;56:68-75.

33. Stevens JA, Sogolow ED. Gender differences for non-fatal unintentional fall related injuries among older adults. Inj. Prev. 2005;11:115-9.

34. Meisler R, Thomsen AB, Theilade P, Abildstrøm H, BORGE P, Treschow M, et al. Age-related differences in mechanism, cause, and location of trauma deaths. Minerva Anestesiol. 2011;77:592-7.
35. Curtis EM, van der Velde R, Moon RJ. Epidemiology of fractures in the United Kingdom 1988-2012: Variation with age, sex, geography, ethnicity and socioeconomic status. Bone. 2016;87:19-26.

36. Kalesan B, Mobily ME, Keiser O, Fagan JA, Galea S. Firearm legislation and firearm mortality in the USA: a crosssectional, state-level study. Lancet. 2016; 387:1847-55.

37. Fahimi J, Larimer E, Hamud-Ahmed W, Anderson E, Schnorr CD, Yen I, et al. Long-term mortality of patients surviving firearm violence. Inj. Prev. 2016;22: 129-34.

38. Fowler KA, Dahlberg LL, Haileyesus T, Annest JL. Firearm injuries in the United States. Prev Med. 2015:79:5-14.

39. Gomez D, Haas B, de Mestral C, Sharma S, Hsiao M, Zagorski B, et al. Gender-associated differences in access to trauma center care: A population-based analysis. Surgery. 2012;152:179-85.

\section{Submit your next manuscript to BioMed Central and we will help you at every step:}

- We accept pre-submission inquiries

- Our selector tool helps you to find the most relevant journal

- We provide round the clock customer support

- Convenient online submission

- Thorough peer review

- Inclusion in PubMed and all major indexing services

- Maximum visibility for your research

Submit your manuscript at www.biomedcentral.com/submit
) Biomed Central 